\title{
Walkability and city users. Critical analysis of opportunities and risks
}

\author{
Ginevra Balletto ${ }^{1}$, Alessandra Milesi ${ }^{1}$, Mara Ladu ${ }^{1}$, Tiziana Campisi ${ }^{2 *}$ and Giuseppe Borruso ${ }^{3}$ \\ 1 Department of Civil and Environmental Engineering and Architecture. University of Cagliari, Italy, \\ balletto@unica.it; maraladu@hotmail.it;; alessandra.milesi@gmail.com \\ 2 Faculty of Engineering and Architecture, University of Enna Kore, Cittadella Universitaria 94100 Enna, \\ Italy, tiziana.campisi@unikore.it \\ 3 Department of Economics, Business, Mathematics and Statistics "Bruno de Finetti", University of Trieste, \\ Via Tigor 22, 34127 Trieste, Italy, giuseppe.borruso@deams.units.it \\ * Corresponding author: Tiziana Campisi, tiziana.campisi@unikore.it
}

Citation: Balletto, G.; Milesi A.; Ladu M.; Campisi, T.; Borruso, G., 2022, Walkability and city users. Critical analysis of opportunities and risks. SUPTM 2022 conference proceedings sciforum-054497. https://doi.org/10.31428/10317/10466

Publisher's Note: UPCT and Sciforum stays neutral with regard to jurisdictional claims in published maps and institutiona affiliations.

Copyright: (c) 2022 by the authors. Submitted for possible open access publication under the terms and conditions of the Creative Commons Attribution (CC BY) license

https://creativecommons.org/licens es/by/4.0/).

\begin{abstract}
Walkability is the subject of an unprecedented multidisciplinary organizational effort, as it affects urban quality and health. Metropolitan cities with SUMPs also intend to improve and promote walkability according to the theoretical approach of the "Walkable City", based on continuity, balance, safety, comfort, accessibility, efficiency and attractiveness of places. With the SUMP, metropolitan cities must also govern the daily flows of city users, 'consumers' of cities, a consequence of economic and socio-cultural dynamics. How and in which communities do SUMPs act? Can the "Walkable City" answer the growing demand for urban mobility? These are the questions that guided the paper.
\end{abstract}

Keywords: Walkability; City users; Sustainable Urban Mobility Plan

\section{Introduction}

The quality of life in cities is closely linked to the presence and spatial distribution of urban services and to the relative accessibility, mono or multimodal. In particular, the walkability allows to detect how much the urban environment is able to respond to the accessibility of the local community and city users (regardless of age and social class). This condition has crossed all shapes, sizes and paradigms of cities, from villages to metropolitan cities. In particular, the metropolitan city - national and international - with its strong commuting to and from the urban center draws attention to the walkability of short networks within the framework of sustainable mobility planning. How and to what extent is walkability included in the Sustainable Mobility Plans to meet the needs of the local community and city users? To try to answer this question, we propose the development of a grid for comparing and evaluating the Sustainable Urban Mobility Plans (SUMP) of the Italian metropolitan cities with the planning policies, with particular reference to the health issues. Such a summary framework could help in tackling the health crisis effects by a new urban design approach [1,2]. The paper is developed in the following paragraphs: state of the art SUMP, walkability in the SUMP, discussions and conclusion.

\section{Sustainable Urban Mobility Plan}

The SUMP is a strategic plan that is based on the principles of integration, participation, monitoring and evaluation to meet the demand for mobility of people and goods with the aim of improving the quality of life [3]. Updated SUMP guidelines have been disseminated since 2013 and have been widely adopted throughout Europe. The 
guidelines have been updated to reflect recent trends in mobility, technology and community.

\subsection{State of the art SUMP}

Below is the summary framework of the European and national legislation of the PUMS and the related objectives (Fig. 1).

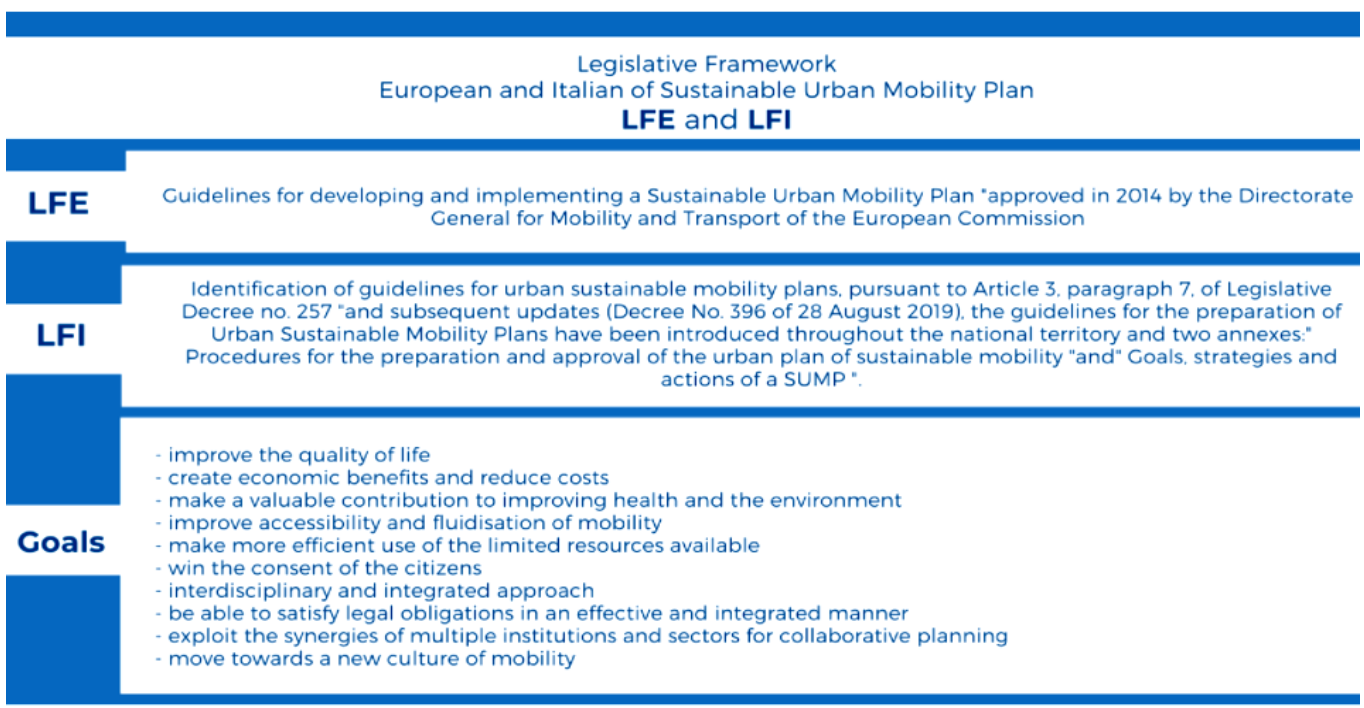

Figure 1. Legislative Framework European and Italian of SUMP and principal Goals (Author: Balletto G, 2021)

The SUMP (titled PUMS in Italy) aims to improve the quality and environmental performance of urban areas in order to ensure a healthier urban system within an overall framework of economic and social sustainability, ensuring the right to mobility, without burdening, as far as possible, on the community in terms of atmospheric and noise pollution, traffic and accidents. There are few metropolitan cities equipped with SUMPs and this increases the gap in sustainable mobility between city-city and cityterritories, with consequences for the community and city users. Below is the state of the art of PUMS in Italy (Fig. 2).

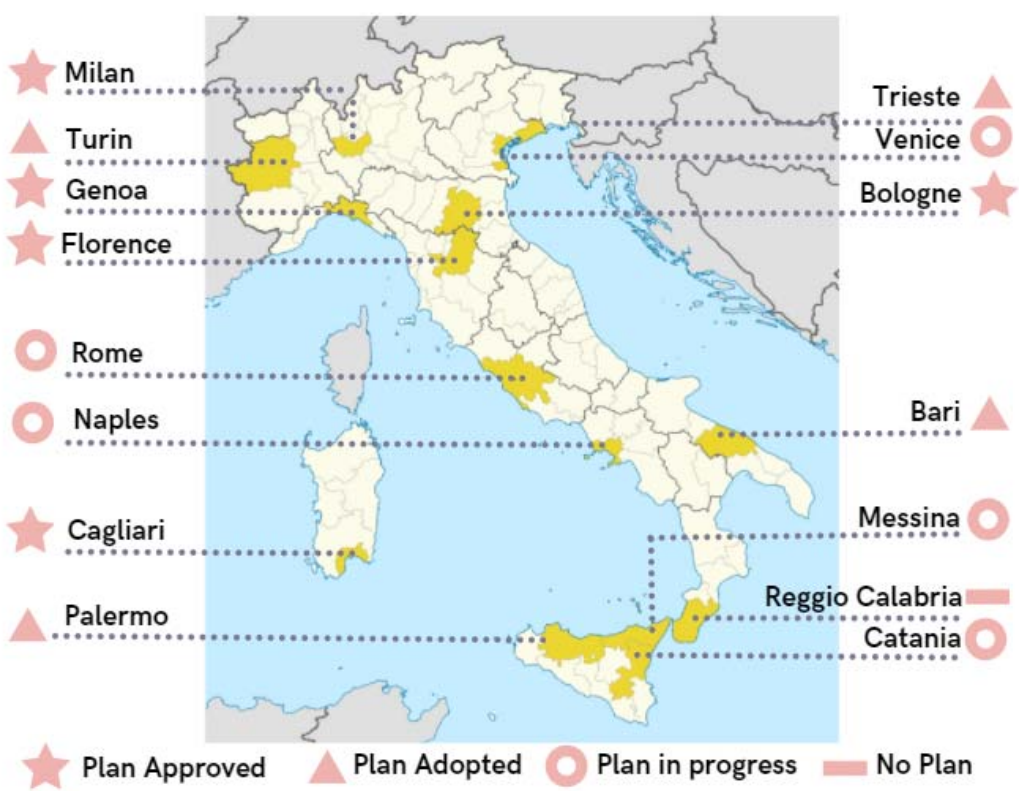

Figure 2. SUMP status in Italian metropolitan cities (Author: Balletto G, 2021) 


\subsection{Walkability in the SUMP}

Active urban mobility contributes to healthier and more socially inclusive cities. In particular, the concept of walkability is related to the quality of life in cities and depends on the presence of spaces, services and activities and their spatial distribution. Several studies in the literature have highlighted the possibility of creating walkability indexes related to different users (workers, tourists, citizens, commuters), both ablebodied and not. Walking is a real panacea for health and does not require excessive physical effort. It has effects on improving mood, self-esteem, and personal balance.

Table 1. Summary framework (Author: Balletto G., 2021). Source: https://www.osservatoriopums.it/ and https://moovitapp.com/insights/en/Moovit Insights_Public Transit Index-countries

\begin{tabular}{|c|c|c|c|c|c|}
\hline $\begin{array}{l}\text { APproved } \\
\text { ADopted }\end{array}$ & SUMP & $\begin{array}{c}\text { Mobility walk, } \\
\text { special areas, slow } \\
\text { and e-mobility and } \\
\text { intermodality }\end{array}$ & $\begin{array}{c}\text { SEA } \\
\text { Strategic } \\
\text { Environment } \\
\text { al } \\
\text { Assessment }\end{array}$ & $\begin{array}{c}\text { How many } \\
\text { people walk for more } \\
\text { than } 1 \mathrm{~km} \\
\text { in the city? }(\%)\end{array}$ & $\begin{array}{c}\text { The average } \\
\text { distance people } \\
\text { in city walk every } \\
\text { day }(\mathrm{km})\end{array}$ \\
\hline $\mathrm{AP}$ & Milan & $\bullet$ & $\bullet$ & 39 & 7.1 \\
\hline $\mathrm{AP}$ & Bologne & $\bullet$ & $\bullet$ & 35 & 6.4 \\
\hline $\mathrm{AP}$ & Genoa & $\bullet$ & $\bullet$ & 24 & 4.4 \\
\hline $\mathrm{AP}$ & Florence & • & • & 24 & 4.3 \\
\hline $\mathrm{AP}$ & Cagliari & • & - & - & - \\
\hline $\mathrm{AD}$ & Turin & $\bullet$ & $\bullet$ & 31 & 5.5 \\
\hline $\mathrm{AD}$ & Trieste & $\bullet$ & • & 25 & 4.6 \\
\hline $\mathrm{AD}$ & Bari & $\bullet$ & $\bullet$ & 23 & 4.2 \\
\hline $\mathrm{AD}$ & Palermo & $\bullet$ & • & 17 & 3 \\
\hline
\end{tabular}

The perception of walking distances by users depends on a number of sociodemographic factors (age, gender, health status) [4], environmental factors (road maintenance, lighting, slope), and socio-cultural factors (nodes such as stores, churches, cultural sites) $[2,5,6]$. Urban planning in metropolitan cities must encourage a modal shift towards modes of transport that ensure environmental, social and economic sustainability, such as walking. At the same time, it should promote a participatory, community-centered framework that raises public awareness of the environmental and health externalities of mobility, promotes greater use of public transport and encourages walking and cycling $[7,8]$.

The interest in walking, seen as an action concomitant to the livability of the city and its quality itself, also in relation to the characteristics to the public space, was born in the immediate post-war period, developing in different points of view. A sustainable and resilient metropolitan city must refer to environmentally integrated spatial planning and a development of soft /slow mobility. Figure 2 reports the diffusion in Italy of SUMP urban planning tools with reference to their adoption and/or approval. Considering the main Italian metropolitan cities.

As from our methodological proposal, to put within a same framework some different elements coming from SUMP, other planning instruments and data useful for the evaluation of some of the urban performances, Table 1 shows the correlation of these urban planning tools with the strategic environmental assessment and the attention paid to walking, highlighting for each context the walking distance generally covered by users. 


\section{Discussion}

Since 2013, metropolitan cities have had to produce plans aimed at sustainable mobility. From our summary, only 5 out of 14 metropolitan cities have approved the SUMP, and therefore with an operational instrument available; 4 have adopted these plans, although not yet approved, while 5 plans are still in progress. This is a critical condition in relation both to the objectives of the 2030 agenda and to the more ambitious green deal. Also, metropolitan cities follow different aims in terms of how to reach a sustainable mobility. Several divides can be observed.

A first separation is among the metropolitan cities with SUMP approved with those that have adopted, as it appears from Figure 2 and Table 1. Another separation deals with how the sustainable mobility is governed. Milan, Bologna, Genoa, Florence put a stronger attention to the active contribution of the walking community. Turin, Trieste, Bari and Palermo intend to govern sustainable mobility through the contribution of the community less inclined to walkability. In such a sense, the role that SUMP communication plays, becomes particularly important and relevant in terms of the related positive externalities on the environment and health for the community it can help reaching.

\section{Conclusions}

Only 4 out of 14 SUMPs show that they act in resilient communities in terms of mobility walks. Table 2 also draws attention to aspects of physical (hills, rivers, other geomorphological and geographical elements) and urban geography (presence of enclaves, urban form, etc.) which constitute the invariants. One of the observations to be drawn, is that walkability of communities and city users is affected by often neglected factors, that do not necessarily appear within the plans and the planning process as a whole, nor the plans are always integrated and spilling-over one to each other. In particular, SUMP, SEA and other ways of integrating a true participation into the planning process are not always matched. A stronger participation accompanying the entire planning process, including monitoring according to the Strategic Environmental Assessment SEA), plays a significant role and should be more adequately considered.

\section{References}

1. Balletto, G., Ladu, M., Milesi, A., \& Borruso, G. (2021). A Methodological Approach on Disused Public Properties in the 15Minute City Perspective. Sustainability, 13(2), 593. https://doi.org/10.3390/su13020593

2. Palumbo, M. E., Mundula, L., Balletto, G., Bazzato, E., \& Marignani, M. (2020, July). Environmental Dimension into Strategic Planning. The Case of Metropolitan City of Cagliari. In International Conference on Computational Science and Its Applications (pp. 456-471). Springer, Cham. DOI 10.1007/978-3-030-58820-5_34

3. Guidelines for developing and implementing a Sustainable Urban Mobility Plan" (2014) https://www.eltis.org/mobilityplans/sump-guidelines

4. Campisi, T., Ignaccolo, M., Inturri, G., Tesoriere, G., \& Torrisi, V. (2021). Evaluation of walkability and mobility requirements of visually impaired people in urban spaces. Research in Transportation Business \& Management, 40, 100592.

5. Balletto G, Ladu M, Milesi A, Borruso G. A Methodological Approach on Disused Public Properties in the 15-Minute City Perspective. Sustainability. 2021; 13(2):593. https://doi.org/10.3390/su13020593

6. Ingram, M., Adkins, A., Hansen, K., Cascio, V., \& Somnez, E. (2017). Sociocultural perceptions of walkability in Mexican American neighborhoods: implications for policy and practice. Journal of transport \& health, 7(B), 172.

7. Tran, M., \& Brand, C. (2021). Smart urban mobility for mitigating carbon emissions, reducing health impacts and avoiding environmental damage costs. Environmental Research Letters, 16(11), 114023. DOI 10.1088/1748-9326/ac302e

8. Blečić, I., Congiu, T., Fancello, G., \& Trunfio, G. A. (2020). Planning and design support tools for walkability: A guide for urban analysts. Sustainability, 12(11), 4405. 